\title{
Phase Behavior and Temperature-Responsive Molecular Filters Based on Self-Assembly of Polystyrene-block-poly( $N$-isopropylacrylamide)-block-polystyrene
}

\author{
Antti Nykänen, ${ }^{\dagger}$ Markus Nuopponen, ${ }^{\ddagger}$ Antti Laukkanen,,$" \#$ Sami-Pekka Hirvonen," \\ Marjaana Rytelä,§ Ossi Turunen, ${ }^{\S}$ Heikki Tenhu, ${ }^{\ddagger}$ Raffaele Mezzenga ${ }^{\perp},{ }^{\prime l}$, \\ Olli Ikkala, ${ }^{\dagger}$ and Janne Ruokolainen*,†
}

\author{
Department of Engineering Physics and Mathematics and Center for New Materials, Helsinki \\ University of Technology, P.O Box 2200, FI-02015 TKK, Finland; Department of Chemistry, University \\ of Helsinki, P.O. Box 55, 00014 Helsinki, Finland; Department of Chemical Technology, Helsinki \\ University of Technology, P.O. Box 6100, FI-02015 TKK, Finland; Department of Physics ad Fribourg \\ Center for Nanomaterials, University of Fribourg, Perolles Fribourg, CH-1700 Switzerland; and Nestlé \\ Research Center, Vers-Chez-les-Blanc, 1000 Lausanne 26, Switzerland
}

\begin{abstract}
This work describes the synthesis of temperature-responsive polystyrene-block-poly( $N$-isopropylacrylamide)-block-polystyrene triblock copolymers, i.e., PS- $b$-PNIPAM- $b$-PS, their self-assembly and phase behavior in bulk, and demonstration of aqueous thermoresponsive membranes. A series of PS- $b$-PNIPAM- $b$-PS triblock copolymers were synthesized using reversible addition-fragmentation chain transfer (RAFT) polymerization. The hydrophobic PS end blocks were selected to form the minority component, whereas the temperatureresponsive PNIPAM midblock accounted for the majority component. The self-assembly and phase behavior in bulk of PS- $b$-PNIPAM- $b$-PS as well as selected blends with low molecular weight PNIPAM homopolymers were studied using transmission electron microscopy (TEM). Classical lamellar, cylindrical, spherical, and bicontinuous double gyroid morphologies were observed in the dried state. In aqueous solutions, the glassy PS domains act as physical cross-links, and hydrogels were therefore formed. The bulk block copolymer morphology had a strong effect on the degree of swelling in aqueous solutions upon cooling below the coil-globule transition temperature of the PNIPAM midblock. Bulk compositions with spherical PS domains and PNIPAM continuous phase swelled in water up to 58 times by weight, whereas composition having cylindrical PS domains or bicontinous gyroid structure in bulk swelled 20 or 10 times by weight, respectively. Finally, lamellar compositions did not show any swelling. Composite membranes for separation studies were prepared by spin-coating thin films of PS- $b$-PNIPAM- $b$-PS on top of meso/macroporous polyacrylonitrile (PAN) support membrane. The permeability was measured as a function of temperature using aqueous mixture of poly(ethylene glycol) (PEG) with several well-defined molecular weights. The permeability showed a temperature switchable on/off behavior, where higher permeability is obtained below transition temperature of PNIPAM, and the molecular cutoff limits for the PEG molecules are surprisingly low-between 108 and $660 \mathrm{~g} / \mathrm{mol}$. The results encourage to further develop and optimize these materials for responsive nanofiltration applications.
\end{abstract}

\section{Introduction}

Stimuli-responsive polymers are attractive materials in which biological materials can be a considerable source for inspiration, as the latter ones often respond to conditions and stimuli. Depending on the specific behavior and application, polymers can be designed to sense and respond to changes in the environmental conditions such as temperature, ${ }^{1-4} \mathrm{pH},{ }^{5-8}$ magnetic or electric fields, ${ }^{9-11}$ ionic strength, ${ }^{12,13}$ added saccharides, ${ }^{14,15}$ antigen binding, ${ }^{16}$ or light. ${ }^{17,18}$ Even multiple functionalities can be combined in order to respond, e.g., to both $\mathrm{pH}$ and temperature due to incorporation of two stimuliresponsive polymers. ${ }^{19-22}$

Poly( $N$-isopropylacrylamide) (PNIPAM) is one of the most extensively investigated synthetic temperature-responsive poly-

* Corresponding author. E-mail: janne.ruokolainen@tkk.fi.

$\dagger$ Department of Engineering Physics and Mathematics and Center for New Materials, Helsinki University of Technology.

$\doteqdot$ University of Helsinki.

$\S$ Department of Chemical Technology, Helsinki University of Technology.

"University of Fribourg.

$\perp$ Nestlé Research Center.

* Current address: Drug Discovery and Development Technology Center, Faculty of Pharmacy, University of Helsinki, Helsinki, Finland. mers. In aqueous solutions it undergoes a coil-globule transition $^{23}$ at a temperature of ca. $32{ }^{\circ} \mathrm{C}$, and this transition temperature can be tuned by copolymerizing hydrophobic or hydrophilic comonomers, ${ }^{24}$ for example acrylic acid comonomers (PNIPAM-rnd-PAA). ${ }^{25}$ PNIPAM-based polymers are attractive in a number of applications, and in particular in the biomedical field, owing to the temperature-responsive behavior in water solutions near the body temperature.

Among the several ways to exploit the conformational transition of PNIPAM to achieve functional behavior, a widely studied concept is based on responsive polymer networks in water solutions to form hydrogels and gelators. The networks can be formed by permanent covalent cross-links, but the possibility to melt, reprocess, or redissolve the material is lost. On the other hand, physical cross-links maintain the processability, as they can successively be broken and re-formed by heating or by dissolving. In the latter case, a common concept is based on ABA triblock copolymers. In the bulk state, they self-assemble into spherical, cylindrical, lamellar, or double gyroid morphologies. ${ }^{26,27}$ The ABA block copolymers can be swollen by midblock selective solvents, leading to the physically cross-linked gels, where the end-block domains form the physical cross-links. Either of the blocks can be stimuli- 
responsive. In order to achieve stimuli-responsive hydrogels, the midblock is water-soluble and stimuli-responsive which can lead to control of gel swelling. By contrast, to achieve stimuliresponsive gelators, the solubility of the end groups is controlled by conditions and stimuli while the midblock remains soluble. The recent literature extensively deals with polymeric gelators, where the temperature response is realized by ABA triblock copolymers, ${ }^{28-30} \mathrm{ABC}$ triblock copolymers, ${ }^{31}$ or random and gradient copolymers. ${ }^{32}$ Protein-based materials have been used to design responsive gelators, ${ }^{33,34}$ where recombinant DNA methods were used to prepare triblock-like proteins undergoing reversible gelation in response to both $\mathrm{pH}$ and temperature due to the coil-to-helix conformation transition. ${ }^{33,35}$

Hydrogels and gelators are relevant in the field biomaterials, since they can be used for targeted drug delivery, sensors, membranes capable of releasing or separating selectively specific substances, or actuators. ${ }^{36-44}$ Even autonomous self-beating systems have been demonstrated using random copolymers, based on swelling/deswelling oscillations due to changes of the ion concentration in the gel, as a consequence of reversible enzymatic reactions. ${ }^{13}$ Stimuli-responsive hydrogels have also been used as components of composite materials. Thermoreversible color changes or light modulation is reported by encapsulating colored responsive PNIPAM hydrogels within a nonresponsive transparent gel matrix; ${ }^{45}$ composite gels are prepared based on poly(methacrylic acid) gel particles dispersed in poly(dimethylsiloxane) (PDMS) rubber, capable of releasing vitamin B12 in a pH-controllable manner; ${ }^{36}$ and solvent-induced gel swelling is used to change the spacing of PS beads dispersed in the PDMS rubber matrix, thus tuning the photonic band gap and optical properties of the material. ${ }^{46}$

Yet, the most extensive application for stimuli-responsive polymer composite materials is probably their use as active components in porous membranes to control permeability and molecular filtration. Composite membranes are commonly realized by coating the surface of an existing porous membrane by a responsive polymeric active layer. ${ }^{7,47-53}$ Upon external stimuli, the chains of the responsive polymer film stretch or collapse, leading to a controllable opening and closing of the membrane pores. Responsive membranes have also been prepared by using chemically cross-linked bulk gels of stimuliresponsive polymer ${ }^{37}$ or by encapsulating the stimuli-responsive polymer in the membrane during the membrane preparation. ${ }^{54-57}$ Such membranes efficiently filter poly(ethylene glycol) (PEG) molecules of size larger than $5000 \mathrm{Da}^{56,57}$ or dextran molecules of size $100 \mathrm{kDa},{ }^{53}$ separate water-isopropanol mixtures, ${ }^{37}$ and control the permeability of fluorescein isothiocyanate-dextran phosphate buffer solution. ${ }^{50}$

A highly demanded improvement of membranes based on hydrogels is to obtain a quicker response to the external stimuli. This response is controlled by diffusion-activated mass transport of the solvent through the gel. Several strategies have been explored for increasing the response dynamics, such as introducing porosity ${ }^{58}$ or by tailoring the hydrogel architecture at the molecular level by grafting either hydrophobic ${ }^{59}$ or hydrophilic $^{60}$ side chains aiding the expulsion of water from the network during the collapse. Since the times needed for swelling and deswelling of the gels are directly proportional to the square of the distance that water has to diffuse, it is, in principle, possible to reduce the response time by decreasing the gel dimensions. ${ }^{61}$ It has been demonstrated that while a $1 \mathrm{~mm}$ thick gel of photo-cross-linked microgels has a characteristic response time scale of several hours, the same gel responds to external

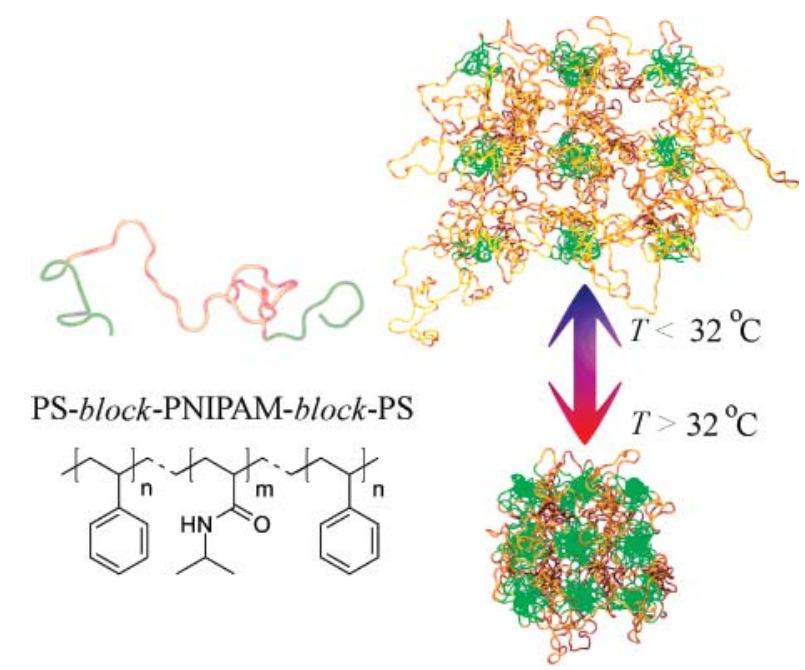

Figure 1. Chemical structure of polystyrene-block-poly( $N$-isopropylacrylamide)-block-polystyrene triblock copolymer. On the right, a schematic illustration of temperature-induced conformation transition of aqueous hydrogel having self-assembled morphology with spherical PS domains. The latter domains act as physical cross-links for the hydrogel, and as the temperature is raised above the coil-globule transition temperature the PNIPAM chains become hydrophobic and the gel collapses.

stimuli within a few second if its thickness is reduced to $300 \mathrm{~nm}^{62}$

In this paper the self-assembly and aqueous swelling behavior of physically cross-linked hydrogels are studied. The system is based on a triblock copolymer, PS- $b$-PNIPAM- $b$-PS, in which the central PNIPAM block acts as the stimuli-responsive block. The weight fraction of PS is varied in order to investigate the phase behavior in bulk and to design novel aqueous hydrogels based on lamellar, gyroid, cylindrical, and spherical block copolymer morphologies. Figure 1 demonstrates the concept to design the stimuli-responsive hydrogels using the spherical bulk morphology. The gel swelling behavior is investigated, and membranes are constructed by spin-coating triblock solutions onto porous support membrane, whereas permeation studies are carried out using a mixture of well-defined low molecular and high molecular weight PEG polymers.

\section{Experimental Methods}

Materials. $N$-Isopropylacrylamide (NIPAM, 99\%, Acros Organics, Belgium) was purified by recrystallization from toluene. 2,2'-Azobis(isobutyronitrile) (AIBN, Aldrich Chemicals, Germany) was purified by recrystallization from methanol. Dioxane (Lab Scan, Ireland) and styrene were distilled prior to use. Homopolymeric poly $(N$-isopropylacrylamide) (PNIPAM), which was used for blend samples, was received from Polymer Source Inc. and was used without further purification $\left(M_{\mathrm{n}}=6100 \mathrm{~g} / \mathrm{mol}, M_{\mathrm{w}} / M_{\mathrm{n}}=1.13\right)$. Tetrahydrofuran (THF, 99\%) was received from Fluka.

Synthesis of the $S, S^{\prime}$-Bis $\left(\alpha, \alpha^{\prime}\right.$-dimethyl- $\alpha^{\prime \prime}$-acetic acid) Trithiocarbonate (BDAT). The target compound was prepared by the method described elsewhere. ${ }^{63}$

Synthesis of Polystyrene (PS). Styrene, BDAT, and AIBN were typically dissolved in 1,4-dioxane. Solutions were degassed by three freeze-pump-thaw cycles. Vessel were sealed under vacuum and placed in a thermostatically controlled oil bath $\left(70{ }^{\circ} \mathrm{C}\right)$ to allow polymerization during a well-defined predetermined time. After the polymerization, the polymer was precipitated in cold methanol and purified by repeated precipitations. The final product was dried in vacuum to yield yellow powders. Polymerization details are listed in Table 1.

Synthesis of the PS- $b$-PNIPAM- $b$-PS Triblock Copolymers. A series of eight different PS- $b$-PNIPAM- $b$-PS triblock copolymers 
Table 1. Details of the Polymerization of Polystyrene Homopolymers

\begin{tabular}{|c|c|c|c|c|c|c|}
\hline polymer & monomer A (concn, solvent, temp) & $\operatorname{BDAT}^{a}(\mathrm{mM})$ & AIBN (mM) & time $(\mathrm{h})$ & $M_{\mathrm{n}}^{b}\left(\mathrm{~g} \mathrm{~mol}^{-1}\right)$ & $M_{\mathrm{w}} / M_{\mathrm{n}}{ }^{b}$ \\
\hline PS-7200 & styrene $\left(4.7 \mathrm{M}, \mathrm{THF}, 60^{\circ} \mathrm{C}\right)$ & 2.9 & 0.6 & 20 & 7200 & 1.21 \\
\hline PS-17700 & styrene $\left(2.2 \mathrm{M}\right.$, dioxane, $\left.70^{\circ} \mathrm{C}\right)$ & 0.8 & 0.8 & 48 & 17700 & 1.57 \\
\hline PS-27600 & styrene $\left(2.2 \mathrm{M}\right.$, dioxane, $\left.70^{\circ} \mathrm{C}\right)$ & 1.3 & 0.8 & 48 & 27600 & 1.50 \\
\hline PS-37000 & styrene $\left(2.9 \mathrm{M}\right.$, dioxane, $\left.70^{\circ} \mathrm{C}\right)$ & 0.9 & 0.9 & 72 & 37000 & 1.55 \\
\hline PS-41000 & styrene $\left(2.2 \mathrm{M}\right.$, dioxane, $\left.70^{\circ} \mathrm{C}\right)$ & 0.7 & 0.8 & 48 & 41000 & 1.38 \\
\hline PS-41200 & styrene $\left(2.2 \mathrm{M}\right.$, dioxane, $\left.70^{\circ} \mathrm{C}\right)$ & 0.7 & 0.8 & 48 & 41200 & 1.31 \\
\hline
\end{tabular}

${ }^{a}$ Chain transfer agent $S, S^{\prime}$-bis $\left(\alpha, \alpha^{\prime}\right.$-dimethyl- $\alpha^{\prime \prime}$-acetic acid) trithiocarbonate. ${ }^{b}$ Determined by SEC using calibration with PS standards.

Table 2. Details of RAFT Polymerizations and the Resulting PS- $b$-PNIPAM- $b$-PS Triblock Copolymers

\begin{tabular}{|c|c|c|c|c|c|c|}
\hline sample code ${ }^{g}$ & $\begin{array}{c}\text { PNIPAM block } \\
{\text { (concn, temp, time })^{a}}\end{array}$ & PS block ${ }^{b}(\text { concn })^{c}$ & $M_{\mathrm{n}}{ }^{d}\left(\mathrm{~g} \mathrm{~mol}^{-1}\right)$ & $M_{\mathrm{w}} / M_{\mathrm{n}}{ }^{e}$ & wt $\%^{f}$ PNIPAM & morphology \\
\hline PN82.40K & $1.0 \mathrm{M}, 70^{\circ} \mathrm{C}, 24 \mathrm{~h}$ & PS-7200 (0.5 mM) & 40500 & 1.44 & 82 & spherical \\
\hline PN79.35K & $1.0 \mathrm{M}, 70^{\circ} \mathrm{C}, 24 \mathrm{~h}$ & PS-7200 (0.8 mM) & 34900 & 1.26 & 79 & spherical \\
\hline PN77.118K & $1.1 \mathrm{M}, 70^{\circ} \mathrm{C}, 20 \mathrm{~h}$ & PS-27600 (1.2 mM) & 118300 & 1.51 & 77 & spherical \\
\hline PN72.25K & $1.0 \mathrm{M}, 70^{\circ} \mathrm{C}, 24 \mathrm{~h}$ & PS-7200 (1.6 mM) & 25400 & 1.23 & 72 & spherical \\
\hline PN72.63K & $2.2 \mathrm{M}, 70^{\circ} \mathrm{C}, 18 \mathrm{~h}$ & PS-17700 (2.8 mM $)$ & 63200 & 1.41 & 72 & cylindrical \\
\hline PN61.106K & $0.9 \mathrm{M}, 70{ }^{\circ} \mathrm{C}, 18 \mathrm{~h}$ & PS-41200 (1.2 mM) & 106000 & 1.52 & 61 & gyroid \\
\hline PN55.91K & $1.0 \mathrm{M}, 70^{\circ} \mathrm{C}, 24 \mathrm{~h}$ & PS-41000 (1.6 mM) & 90500 & 1.26 & 55 & lamellar \\
\hline PN43.65K & $0.7 \mathrm{M}, 70^{\circ} \mathrm{C}, 18 \mathrm{~h}$ & PS-37000 (1.3 mM) & 64600 & 1.27 & 43 & lamellar \\
\hline
\end{tabular}

${ }^{a}$ Polymerizations were conducted in 1,4-dioxane. ${ }^{b}$ RAFT macro-transfer agent. ${ }^{c}$ Chain transfer agent $S, S^{\prime}$-bis $\left(\alpha, \alpha^{\prime}\right.$-dimethyl- $\alpha^{\prime \prime}$-acetic acid) trithiocarbonate. ${ }^{d} M_{\mathrm{n}}$ of the A-B block copolymer determined with ${ }^{1} \mathrm{H}$ NMR spectroscopy. ${ }^{e}$ Determined by SEC using calibration with PS standards. ${ }^{f}$ Determined with ${ }^{1} \mathrm{H}$ NMR spectroscopy. ${ }^{g}$ Sample notation is as follows: the value after PN label (PN $=$ poly $(N$-isopropylacrylamide)) is the total weight fraction of the PNIPAM in the PS- $b$-PNIPAM- $b$-PS sample. The second number is the total molecular weight of the sample $\left(\mathrm{g} \mathrm{mol}^{-1}\right)$.

were synthesized via reversible addition-fragmentation chain transfer polymerization of NIPAM using well-characterized PS precursors as macro RAFT-agents. ${ }^{64,65}$ BDAT is a bifunctional RAFT agent. Thus, synthesized block copolymers are $\mathrm{A}-\mathrm{B}-\mathrm{A}$ triblock polymers with PS as an A block and PNIPAM as a B block. SEC shows that the PS block is fully incorporated into the triblock copolymer, and monomodal SEC traces prove pure triblock copolymers. PS was dissolved in 1,4-dioxane before adding NIPAM and AIBN. The mixture was stirred for $30 \mathrm{~min}$ at room temperature to dissolve all the components. The solution was degassed by three successive freeze-pump-thaw cycles ( $<1 \mathrm{mbar}$ ). The polymerization reaction was started by placing the mixture in an oil bath at $70{ }^{\circ} \mathrm{C}$. The reaction was stopped by cooling the solution to ambient temperature. The product was purified by two reprecipitations from THF into diethyl ether and cold water. The product was freed from the homopolymer PNIPAM by centrifugation at $29{ }^{\circ} \mathrm{C}(45 \mathrm{~min}$, $5000 \mathrm{rpm})$. When the length of PS block was only $7200 \mathrm{~g} / \mathrm{mol}$, the precipitation into cold water was not possible, however. In those cases, the product was freed from the homopolymer PNIPAM by dissolving the mixture in cold water and precipitating the block copolymer by centrifugation at $29{ }^{\circ} \mathrm{C}$ (45 min, $\left.5000 \mathrm{rpm}\right)$. This procedure was repeated three times. Purified polymers were freezedried. The structure and purity of the polymers were ascertained by ${ }^{1} \mathrm{H}$ NMR spectroscopy with a $200 \mathrm{MHz}$ Varian Gemini 2000 spectrometer using deuterated chloroform as a solvent: $\delta(\mathrm{ppm}$, $\left.\mathrm{CDCl}_{3}\right): 6.3-7.2(5 \mathrm{H}, \mathrm{Ar}-\mathrm{H}), 4.0(1 \mathrm{H},-\mathrm{NCH}-), 0.8-2.4(3 \mathrm{H}$, PS backbone and $9 \mathrm{H}$, PNIPAM $-\mathrm{CH}_{3}$ and the backbone protons). Molecular weight of PNIPAM block was calculated by comparing the integral of $6.3-7.2(5 \mathrm{H}, \mathrm{Ar}-\mathrm{H})$ to $4.0(1 \mathrm{H},-\mathrm{NCH}-)$. Polymerization details are listed in Table 2.

Bulk Sample Preparation. Polymers were dissolved in THF to yield $1.0 \mathrm{wt} \%$ solutions. To prepare the PS- $b$-PNIPAM- $b$-PS/ PNIPAM blends, the separate THF solutions of PS- $b$-PNIPAM- $b$ PS and PNIPAM were combined according to the desired blend composition, and the solutions were stirred for at least $4 \mathrm{~h}$. The solvent was evaporated at room temperature, and the samples were dried in vacuum at room temperature for $4-6 \mathrm{~h}$ and annealed at ca. $180{ }^{\circ} \mathrm{C}$ under a high vacuum $\left(10^{-8} \mathrm{mbar}\right)$ for $3-4$ days.

Swelling Experiments. Annealed and dried samples were weighted and immersed in Millipore water. The water temperature was stepwise risen from $4{ }^{\circ} \mathrm{C}$ to $15,25,35,45$, and $55^{\circ} \mathrm{C}$. At each step the temperature was let to stabilize for at least $1 \mathrm{~h}$, after which the sample was taken out from the water container, and the gel surface was gently dried with a filter paper (Shleicher and

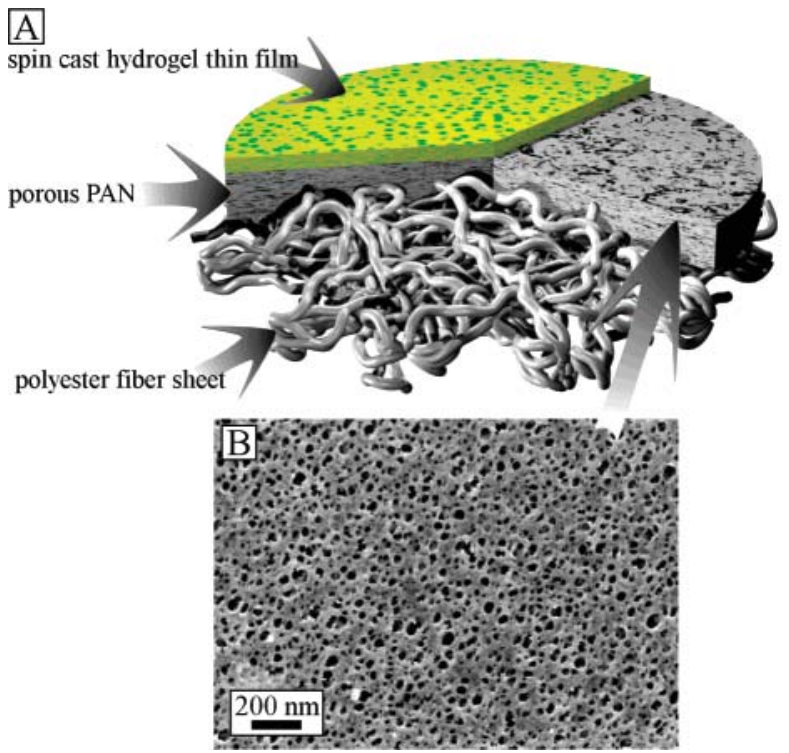

Figure 2. (A) Schematic view of the multilayer composite filter. (B) SEM micrograph of the top surface demonstrating the meso/ macroporous structure of the porous support membrane consisting of a polyacrylonitrile (PAN) layer on top of the polyester fiber support fleece.

Schuell 5892). The surface dried sample was weighted and photographed.

Filtration Experiments. Thin films were spin-coated on top of a porous support membrane consisting of a polyacrylonitrile (PAN) layer on a polyester fiber support fleece, as received from GKSS Research Centre Geesthacht GmbH, Geesthacht, Germany (Figure 2 ). The support membrane has a diameter of $25 \mathrm{~mm}$. The PAN layer had thickness of ca. $10 \mu \mathrm{m}$, and pores were in the range 10$70 \mathrm{~nm}$ with irregular shapes and size distribution (see Figure 2B). The polyester fiber support fleece below the PAN layer consisted of randomly oriented fibers with diameter of ca. $10 \mu \mathrm{m}$. The thickness of the support membrane was $\sim 0.2 \mathrm{~mm}$. For spin-casting, $60 \mu \mathrm{L}$ of $7.5 \mathrm{wt} \%$ THF solution of PS- $b$-PNIPAM- $b$-PS was dropped on the center of the support membrane, which was spinning at speed $1000 \mathrm{rpm}$. Thin films were dried in the same manner as the bulk samples. In addition for some of the samples, annealing in THF vapor for several hours at room temperature was used in 
order to improve the thin film morphology. Figure 2 illustrates the layered structure of the membranes described in this work.

The filtration experiments were performed below and above the transition temperature of PNIPAM, i.e., at 4 and at $60{ }^{\circ} \mathrm{C}$, respectively, to study the effect of temperature on the filtration. The membranes were immersed in water at the given temperature for at least $1 \mathrm{~h}$ before the experiment to stabilize the swelling of the PNIPAM block. Ultrafiltration cell model 8003 from Millipore was used. The filtration cell was connected to nitrogen gas line, and by applying 4 bar pressure the solution was pushed through the membrane. To probe the permeability, an aqueous mixture of six different poly(ethylene glycol) (PEG) molecules of molecular weights of 108, 660, 1130, 5400, 30800 , and $187000 \mathrm{~g} / \mathrm{mol}$ was used where the total PEG concentration was $0.2 \mathrm{wt} \%$. The filtered solution was collected for size exclusion chromatography (SEC) analysis. The relative concentration of each PEG component in the filtered solution was determined by comparing the peak areas of each PEG component in the original and filtered solutions.

Size Exclusion Chromatography (SEC) for the Synthesis Analysis. Measurements were performed with a Waters liquid chromatography system equipped with a Waters 2410 differential refractometer and a Waters $2487 \mathrm{UV}$ as detectors. Three Styragel columns (HR2, HR4, HR6) were used in series. HPLC-grade THF was used as an eluent with a flow rate of $0.8 \mathrm{~mL} / \mathrm{min}$ at $35{ }^{\circ} \mathrm{C}$.

Size Exclusion Chromatography for the Filtration Analysis. Measurements were performed with a Waters Alliance 2690 liquid chromatography system equipped with a RI Waters 2414 detector. Three Shodex columns (OH pak SB 802 HQ, OH pak SB 802,5 HQ, OH pak SB 803 HQ) from Showa Denko were used in series. Water was used as an eluent with a flow rate of $0.7 \mathrm{~mL} / \mathrm{min}$ at $50{ }^{\circ} \mathrm{C}$.

Transmission Electron Microscopy (TEM). The bulk samples were glued on top of microtome sample holder tip and sectioned using Leica Ultracut UCT ultramicrotome with a Diatome diamond knife at temperature $-100{ }^{\circ} \mathrm{C}$. Sections thickness of ca. $70 \mathrm{~nm}$ were collected on 600-mesh size copper grids. For spin-coated membranes the sample preparation was done as follows. Pieces of the membranes were embedded into epoxy (Ebonate 12, Electron Microscopy Science). Before the embedding, membranes were carbon-coated and the epoxy was precured at $60{ }^{\circ} \mathrm{C}$ for $3 \mathrm{~h}$ to minimize the epoxy diffusion into the sample. Thereafter, curing of the epoxy was continued overnight. Cross-sectional thin sections of the membrane were cryo-cut at $-37{ }^{\circ} \mathrm{C}$ using $50 / 50$ solution of DMSO (Fluka)/water in which PNIPAM is insoluble.

\section{Results and Discussion}

PS- $\boldsymbol{b}$-PNIPAM- $\boldsymbol{b}$-PS Structures in Bulk. The self-assembled morphologies in bulk were characterized using TEM. Figure 3 shows the lamellar, gyroid, cylindrical/wormlike, and spherical structures for PS- $b$-PNIPAM- $b$-PS with 43, 61, 72, and $77 \mathrm{wt}$ $\%$ PNIPAM, respectively, i.e., samples PN43.65K, PN61.106K, PN72.63K, and PN77.118K. Compositions with a minor fraction of PNIPAM were not investigated as they were not expected to swell efficiently in aqueous solutions.

In order to additionally tune the compositions for phase diagram studies of block copolymers, a well-known method was also employed to blend relatively low molecular weight homopolymers in the block copolymer. ${ }^{66}$ Therefore, low molecular weight PNIPAM homopolymer $\left(M_{\mathrm{n}}=6100 \mathrm{~g} / \mathrm{mol}\right)$ was blended with PN55.91K and PN43.65K, which had PNIPAM block lengths $M_{\mathrm{n}}{ }^{\text {PNIPAM }}=49500 \mathrm{~g} / \mathrm{mol}$ and $M_{\mathrm{n}}{ }^{\text {PNIPAM }}=27600 \mathrm{~g} / \mathrm{mol}$, respectively, and had lamellar structures without blending. The short length of the homopolymer chain length allowed sufficient difference in chemical potential with respect to PNIPAM block and thus sufficient penetration into the PNIPAM blocks, leading to conditions of "wet brush", ${ }^{67,68}$ Blending PNIPAM homopolymer leads to new structures: for example, pure PN55.91K (55 wt $\%$ PNIPAM, $M_{\mathrm{n}}{ }^{\text {total }}=90500 \mathrm{~g} / \mathrm{mol}$ ) triblock copolymer
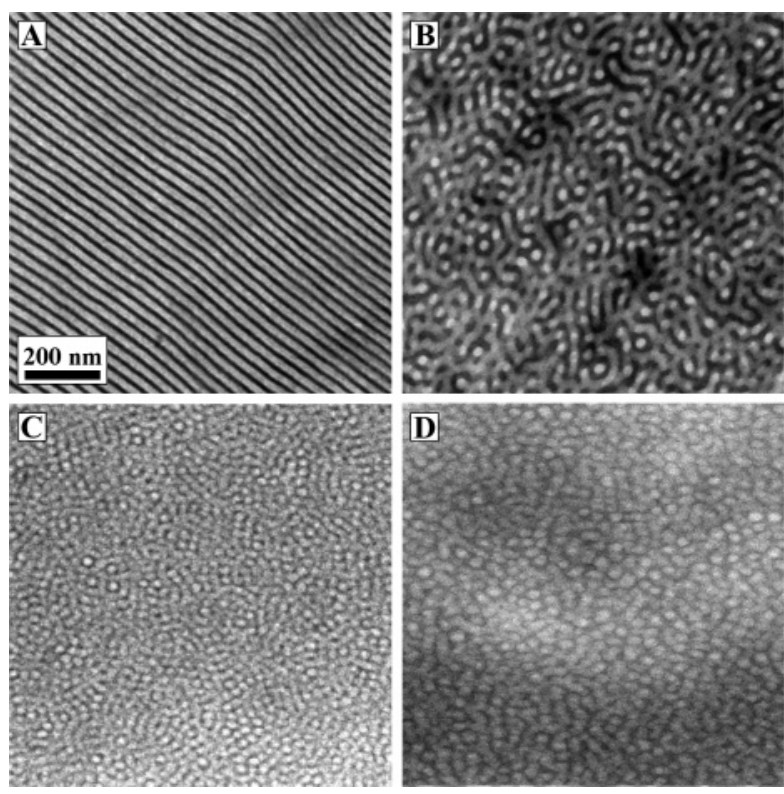

Figure 3. Representative TEM micrographs of pure PS- $b$-PNIPAM$b$-PS triblock copolymers in bulk: (A) PN43.65K (43 wt \% PNIPAM) is lamellar, (B) PN61.106K (61 wt \% PNIPAM) is gyroid, (C) PN72.63K (72 wt \% PNIPAM) is cylindrical/wormlike, and (D) PN77.118K is spherical.

is lamellar in bulk but becomes cylindrical and then spherical upon addition of PNIPAM homopolymer (Figure 4), as the total weight fraction of PNIPAM is increased from $55 \mathrm{wt} \%$ to 66 and $76 \mathrm{wt} \%$, respectively.

The observed morphologies are quite expected: At the strongsegregation limit, the ABA triblock copolymer phase diagram can be considered to be similar to that of $\mathrm{AB}$ diblock copolymers with half of the molecular weight of the corresponding ABA. ${ }^{26,69}$ In this work, the observed structures were plotted into molecular weight/composition diagram in order to illustrate the phase behavior for the PNIPAM-rich compositions (see Figure 5). At 72 wt \% PNIPAM, spherical and cylindrical morphologies are observed for both low and high molecular weights, respectively, as may be expected by a change from the weakly to strongly segregated regimes. However, the structure remains spherical beyond 77 wt \% PNIPAM in all studied cases, irrespective of the PS- $b$-PNIPAM- $b$-PS molecular weight.

Aqueous Swelling. The purpose of the aqueous swelling experiments was to study permeation through the gels as a function of the temperature. Upon immersing PS- $b$-PNIPAM$b$-PS in water, the PNIPAM middle block is expected to swell at temperatures below its coil-globule transition temperature of ca. $32{ }^{\circ} \mathrm{C}$, thus forming network structures, i.e., gels, due to the physical cross-links by the hydrophobic PS domains. The self-assembled bulk structure is expected to strongly affect the extent of swelling due to the shapes of the glassy PS domains. As temperature is increased beyond the transition temperature, also PNIPAM becomes hydrophobic, causing a tendency toward conformational collapse. Results of the aqueous swelling experiments are shown in Figure 6 as a function of temperature for the different bulk morphologies of PS- $b$-PNIPAM- $b$-PS. The vertical axis depicts the weight ratio between the wet and dry PS- $b$-PNIPAM- $b$-PS, while the horizontal axis gives the temperature at which the water uptake is measured. Above ca. $35^{\circ} \mathrm{C}$, no swelling is observed for any of the morphologies, as both PS and PNIPAM are hydrophobic. As expected, PS- $b$ PNIPAM- $b$-PS with spherical bulk morphology swells most as the glassy PS spheres do not restrict expansion in any direction. By cooling, sample PN79.35K (79 wt $\%$ PNIPAM, $M_{\mathrm{n}}{ }^{\text {total }}=$ 

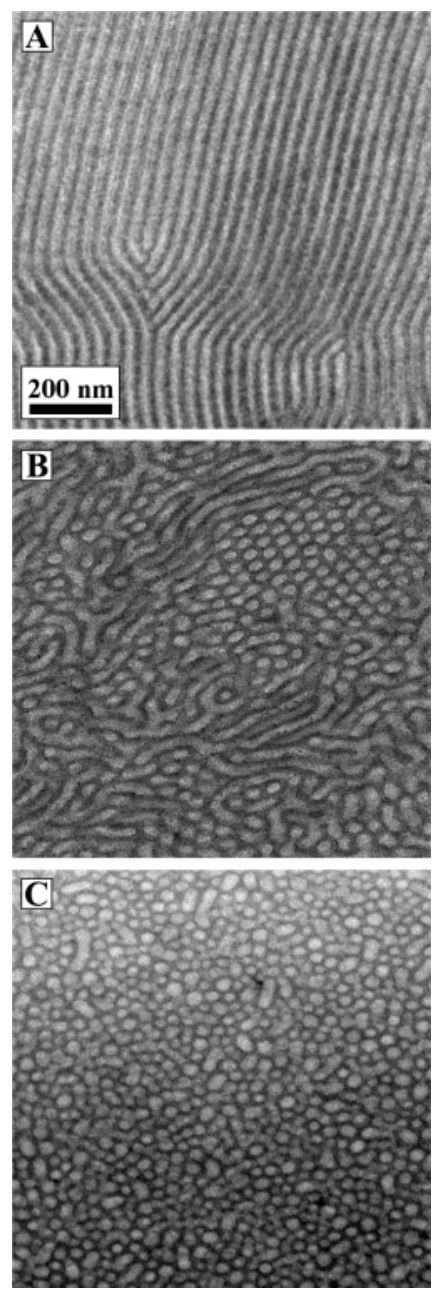

Figure 4. TEM micrographs of PS- $b$-PNIPAM- $b$-PS/PNIPAM blends based on PN55.91K (55 wt \% PNIPAM, $M_{\mathrm{n}}{ }^{\text {total }}=90500 \mathrm{~g} / \mathrm{mol}$ ). (A) Without added homopolymer a lamellar morphology is observed. (B) $76 / 24 \mathrm{w} / \mathrm{w}$ blend is cylindrical. (C) Blend 53/47 w/w is spherical.

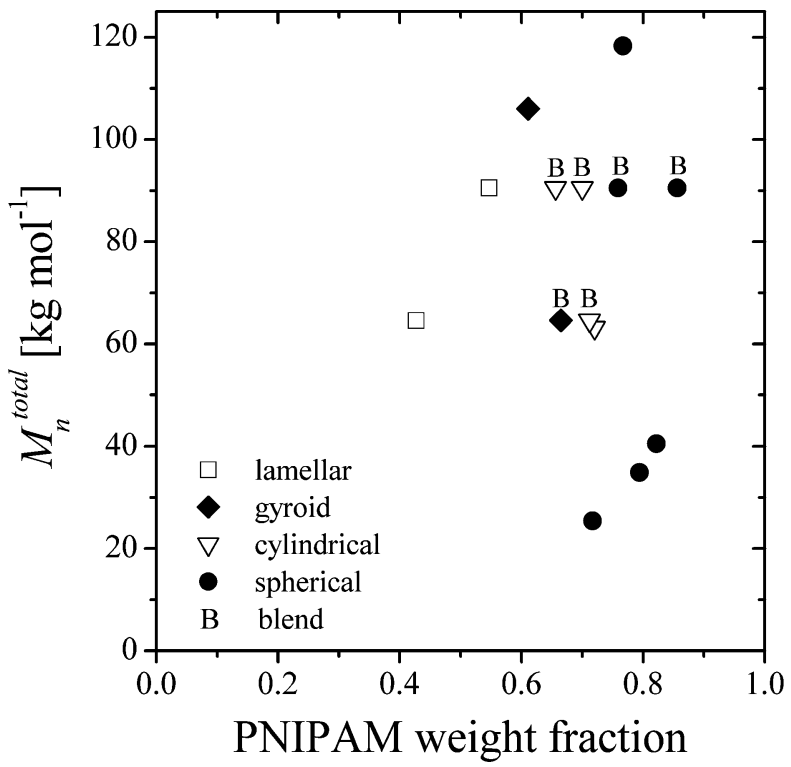

Figure 5. Observed block copolymer morphologies of PS- $b$-PNIPAM$b$-PS and PS- $b$-PNIPAM- $b$-PS/PNIPAM blends in bulk.

$34900 \mathrm{~g} / \mathrm{mol}$ ) swells ca. 58 times of its dry weight. Not unexpectedly, the lowest swelling is observed for PS- $b$ PNIPAM- $b$-PS having lamellar morphology in bulk, where swelling was not observed at all. In this case, the glassy and

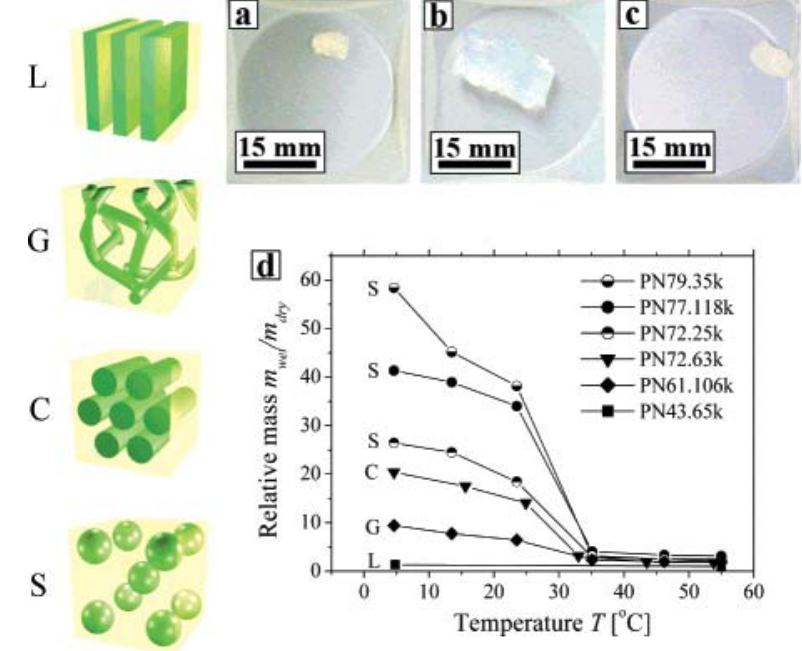

Figure 6. Swelling of PS- $b$-PNIPAM- $b$-PS hydrogels. (A) A photograph of dry PN77.118K sample $\left(77 \mathrm{wt} \%\right.$ PNIPAM, $M_{\mathrm{n}}^{\text {total }}=$ $118300 \mathrm{~g} / \mathrm{mol}$ ). (B) The same sample at $5{ }^{\circ} \mathrm{C}$ in water solution and (C) the same sample at $55{ }^{\circ} \mathrm{C}$ in water solution. (D) Relative gel mass $m_{\text {wet }} / m_{\text {dry }}$ plotted as a function of temperature. The morphologies as labeled as lamellar (L), gyroid $(\mathrm{G})$, cylindrical (C), and spherical (S).

lamellar PS domains hinder the diffusion of water in the direction orthogonal to the lamellae, and water transport through the entire sample is reduced. Second, the glassy PS lamellar domains have fixed shapes and in principle allow swelling of the PNIPAM domains only in the orthogonal direction vs the lamellar plane. Finally, since the lamellar phase is not oriented, there exists a large number of defects and grain boundaries between the glassy PS domains, thus effectively causing mutual interlocking between the glassy PS lamellae. In the bicontinuous gyroid morphology, penetration and diffusion of water are not hindered along any specific direction, since both PS and PNIPAM phases are in principle continuous throughout the material, thus allowing free expansion of the gel. Yet, the presence of a three-dimensional percolating glassy PS skeleton restricts the swelling of the PNIPAM domains, and therefore sample PN61.106K (61 wt \% PNIPAM, $M_{\mathrm{n}}{ }^{\text {total }}=106300$ $\mathrm{g} / \mathrm{mol}$ ) swells up to 10 times. In the cylindrical morphology where PS forms cylinders and PNIPAM the continuous phase, the expansion in the direction radial to cylinders is unrestricted, while in the direction parallel to the cylinders the PS the swelling is reduced. The larger degree of swelling observed for cylinders (up to 20) as compared to the gyroid phase is therefore due to the reduced reinforcing effect of the glassy cylinders in comparison to that of the gyroid skeleton. Finally, for each case, the swelling is reversible upon heating and cooling, and the absorbed water can be released by increasing the temperature above the coil-globule transition temperature.

Filtration Experiments. The temperature-responsive separation was studied using thin films of PS- $b$-PNIPAM- $b$-PS spincast on the porous PAN support membrane. The cutoff molecular weight of the PAN support membrane was above $30 \mathrm{~kg} / \mathrm{mol}$; i.e., rather large molecules can permeate without essentially hindered through it. Two PS- $b$-PNIPAM- $b$-PS block copolymers were selected for closer filtration studies, both having a continuous PNIPAM phase in the annealed bulk state with either self-assembled spherical (PN77.118K, PNIPAM $77 \mathrm{wt} \%, M_{\mathrm{n}}{ }^{\text {total }}=118300 \mathrm{~g} / \mathrm{mol}$ ) or gyroid (PN61.106K, PNIPAM 61 wt $\%, M_{\mathrm{n}}{ }^{\text {total }}=106300 \mathrm{~g} / \mathrm{mol}$ ) structure. Crosssectional TEM micrographs of a spin-coated polymer films on the PAN support membrane are shown in Figure 7a,b. The thickness of the film was of the order of $500-1000 \mathrm{~nm}$, and 


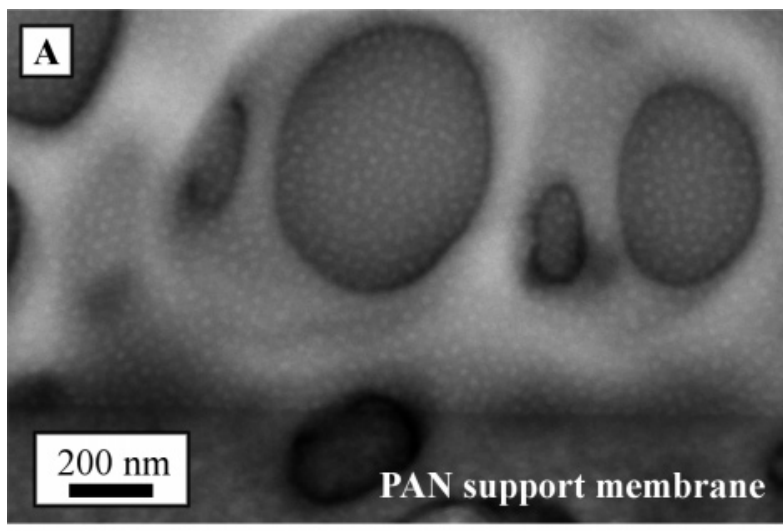

B

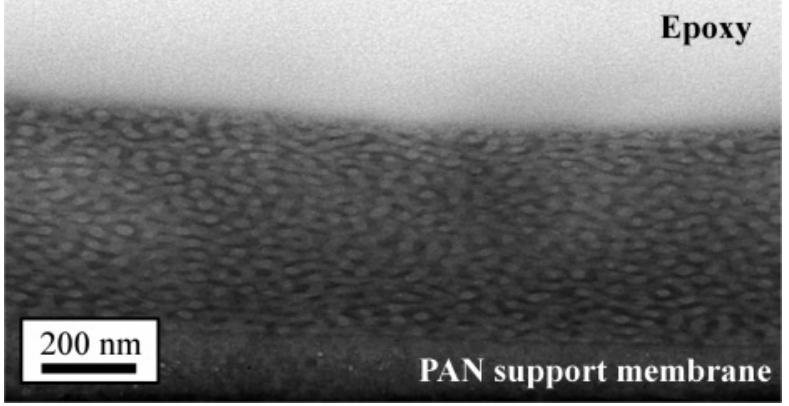

Figure 7. Cross-sectional TEM images of spin-coated thin films of PS- $b$-PNIPAM- $b$-PS on top of the porous polyacrylonitrile support membranes. (A) Sample PN77.118K (77 wt \% PNIPAM, $M_{\mathrm{n}}^{\text {total }}=$ $118300 \mathrm{~g} / \mathrm{mol}$ ), sectioned on holey carbon support film grid, shows a clear spherical morphology similar to corresponding bulk sample and (B) sample PN61.106K (61 wt \% PNIPAM, $M_{\mathrm{n}}^{\text {total }}=106300 \mathrm{~g} / \mathrm{mol}$ ), which in the well-annealed bulk state exhibits a gyroid structure with PNIPAM forming the majority phase form a less ordered bicontinuous morphology. The samples were stained with iodine, which selectively stains to dark the PNIPAM domains.

the samples were solvent annealed in THF vapor; however, because of the lack of thorough thermal annealing, the films showed morphologies with a lower degree of order as compared to bulk samples.

Filtration experiments were carried out at two temperatures: at $4{ }^{\circ} \mathrm{C}$, which is below the coil-globule transition temperature of PNIPAM, and at $60^{\circ} \mathrm{C}$, which is well above. The solution to be filtered consists of an aqueous mixture of six different molecular weights of poly(ethylene glycol) (PEG). The molecular cutoff of the composite membrane in filtration is shown in Figure 8, and evidence for thermoresponsive filtration is given in Table 3. Figure 8 illustrates the relative concentrations $c / c_{0}$ of the different molecular weight PEG mixture components after the filtration for different PEG molecular weights $\left(c_{0}=0.2 \%\right.$ is the initial total PEG concentration before filtration, and $c$ is the corresponding concentration after the filtration, respectively). The solid and open circles represent filtration carried out at 4

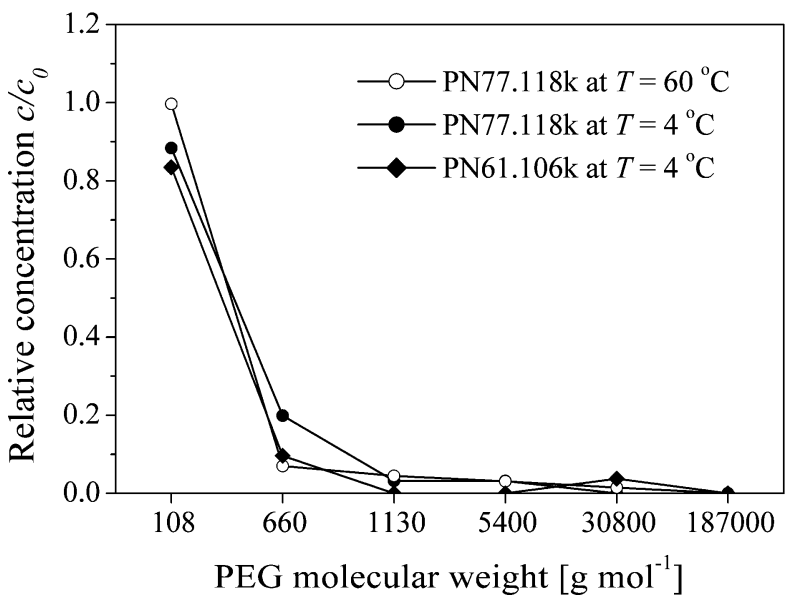

Figure 8. Relative concentration of the PEG components after the filtration using the composite membranes consisting PS- $b$-PNIPAM$b$-PS triblock copolymer thin film on top of the porous polyacrylonitrile support membranes. Two block copolymers with two different bulk structures were used: spherical PS domains (PN77.118K) and gyroid (PN61.106K). Permeation curve with solid circles refer to filtration data acquired at $4{ }^{\circ} \mathrm{C}$ and open circles at $60{ }^{\circ} \mathrm{C}$ for PN77.118K. The curve with diamond refers to the filtration at temperature $4{ }^{\circ} \mathrm{C}$ for PN61.106K. Cutoff molecular weight for polyacrylonitrile support membrane was measured to be high, i.e., above $30 \mathrm{~kg} / \mathrm{mol}$.

and $60{ }^{\circ} \mathrm{C}$, respectively, using PS- $b$-PNIPAM- $b$-PS with a spherical bulk morphology (PN77.118K). The diamonds refer to the filtration carried out at $4{ }^{\circ} \mathrm{C}$ using PS- $b$-PNIPAM- $b$-PS with gyroid bulk morphology (PN61.106K). The solution permeability at $60{ }^{\circ} \mathrm{C}$ for the latter membrane was so low that we did not manage to acquire sufficient amount solution for further analysis.

For both membranes, i.e., PS- $b$-PNIPAM- $b$-PS having spherical (PN77.118K) and gyroid (PN61.106K) bulk structures, the PEG dimers of molecular weight $108 \mathrm{~g} / \mathrm{mol}$ permeate the membrane with less than $20 \%$ rejection (Figure 8). By contrast, PEG $660 \mathrm{~g} / \mathrm{mol}$ is rejected as much as $80-90 \%$, and a total rejection is observed for components with larger PEG molecular weights. Therefore, the molecular cutoff for the spherical structures below and above the coil-globule transition temperature and for gyroid structure below the transition temperature was surprisingly similar (for the gyroid morphology above the transition temperature permeability was practically zero, and therefore the molecular cutoff was not measurable). These findings are relevant also because they set the filtration cutoff molecular weight down to the nanofiltration regime and are substantially smaller than in silica-elastin-like polypeptide and silica-PNIPAM composite membranes, respectively, where the cutoff molecular weights are in the range 1000 and $5000 \mathrm{~g} / \mathrm{mol}^{.}{ }^{56}$

The permeability at temperatures below and above the coilglobule transition temperature of PNIPAM is shown in Table 3. The permeability of the pure PAN meso/macroporous support membrane increases considerably at higher temperatures. A

Table 3. Membrane Permeabilities As Measured by Using Aqueous PEG Solutions at Temperatures below and above the Coil-Globule Transition Temperature of PNIPAM

\begin{tabular}{|c|c|c|c|c|c|}
\hline \multirow[b]{2}{*}{ sample } & \multirow[b]{2}{*}{ structure } & \multirow[b]{2}{*}{ PNIPAM weight fraction (wt \%) } & \multirow{2}{*}{$\begin{array}{c}M_{\mathrm{n}}^{\text {total }} \text { of } \\
\text { PS- } b \text {-PNIPAM- } b \text {-PS }\left(\mathrm{g} \mathrm{mol}^{-1}\right)\end{array}$} & \multicolumn{2}{|c|}{ permeability $\left(\mathrm{L} /\left(\mathrm{m}^{2} \mathrm{~h}\right.\right.$ bar $\left.)\right)$} \\
\hline & & & & $4^{\circ} \mathrm{C}$ & $60{ }^{\circ} \mathrm{C}$ \\
\hline PAN support membrane & meso/macroporous & & & 18.13 & 53.78 \\
\hline $\begin{array}{l}\text { PS- } b \text {-PNIPAM- } b \text {-PS } \\
\text { (PS77.118K) film on }\end{array}$ & $\begin{array}{l}\text { PS- } b \text {-PNIPAM- } b \text {-PS } \\
\text { spherical in bulk }\end{array}$ & 77 & 118300 & 1.04 & 0.05 \\
\hline $\begin{array}{l}\text { PS- } b \text {-PNIPAM- } b \text {-PS } \\
\text { (PS61.106K) film on }\end{array}$ & $\begin{array}{l}\text { PS- } b \text {-PNIPAM- } b \text {-PS } \\
\text { gyroid in bulk }\end{array}$ & 61 & 10600 & 0.32 & $\approx 0$ \\
\hline
\end{tabular}


potential reason is the increased thermal motion of PEG polymers as well as the reduced surface tension and viscosity of the solution. Table 3 shows that the composite membranes consisting of thin PS- $b$-PNIPAM- $b$-PS films of either spherical or gyroid bulk structures show considerably reduced permeability at $60{ }^{\circ} \mathrm{C}$ in comparison to that measured at $4{ }^{\circ} \mathrm{C}$, indicating temperature-responsive filtration. This is the result of hydrophilic/hydrophobic transition of the PNIPAM block of PS- $b$-PNIPAM- $b$-PS as a function of increased temperature. This leads to reduced transport of aqueous PEG solutions within the PNIPAM domains, as soon as the transition temperature of the PNIPAM is passed by heating. Below the transition temperature PNIPAM is hydrophilic, and this allows water and PEG molecules to penetrate, diffuse, and swell the PNIPAM domains. Therefore, the present membranes using PS- $b$-PNIPAM- $b$-PS block copolymer films exhibit reversed thermal behavior as compared to most of the previously reported stimuli-responsive membranes, in which permeability is reduced in cooling below the transition temperature. ${ }^{47,48,50,51,53,56}$ The latter membranes are usually designed using different concepts, where the stimuliresponsive polymer is often directly grafted to pore walls. In such a scenario, in the swollen state the stretched stimuliresponsive polymer brushes fill the pores and essentially close the channels. By increasing the temperature above the coilglobule transition temperature, the polymer brushes collapse to the pore walls and reopen the channels activating water diffusion. Because of the different filtration mechanisms, high efficiency, and reversed temperature-dependent behavior, the membranes described here are expected to offer alternative solutions and complementary possibilities in the filtration technology.

\section{Conclusions}

A series of eight different temperature-responsive PS- $b$ PNIPAM- $b$-PS triblock copolymers were synthesized via reversible addition-fragmentation chain transfer polymerization of NIPAM using a PS precursor as a macro-RAFT agent. The selfassembled bulk morphologies of the triblock copolymers as well as blends of PS- $b$-PNIPAM- $b$-PS with a low molecular weight homopolymer PNIPAM were studied, and the phase behavior was investigated using TEM. Only PNIPAM-rich compositions relevant for membranes were studied. All the classical stable block copolymer morphologies were observed, i.e., lamellar, cylindrical, spherical, and double gyroid structures. The swelling due to water uptake to the PNIPAM domains was studied as a function of temperature. The self-assembled bulk morphology plays an important role in the aqueous swelling: PS- $b$-PNIPAM$b$-PS having spherical self-assembled glassy PS domains in bulk swell at $4{ }^{\circ} \mathrm{C} 58$ times the dry weight, as a consequence of unrestricted water diffusion and three-dimensional swelling coefficient. On the other hand, PS- $b$-PNIPAM- $b$-PS with lamellar structure in bulk does not swell in water at any temperature, as a consequence of restricted water diffusion and glassy polystyrene layer defects. The gyroid and cylindrical morphologies fall between these two extreme cases. Composite membranes were constructed by spin-coating thin PS- $b$-PNIPAM$b$-PS films having spherical or gyroid bulk structures on a porous polyacrylonitrile support membranes. Filtration experiments were performed below and above the coil-globule transition temperature of PNIPAM using an aqueous mixture consisting of six different PEG polymer components. It was demonstrated that (i) the molecular cutoff for PEG polymer was as low as of ca. $660 \mathrm{~g} / \mathrm{mol}$ both for the spherical and gyroid cases, which shows that the membranes can efficiently separate even low molecular weight species; (ii) that the permeability of the membrane had a on/off temperature switchable behavior with increased permeability below coil-globule transition temperature; and (iii) such a temperature behavior is opposite as compared to common thermoreversible composite polymer membranes. Given the simplicity of the concept, we expect that these temperature-responsive membranes allow new possibilities in the field of nanofiltration.

Acknowledgment. This work was carried out in the Centre of Excellence of Finnish Academy ("Bio- and Nanopolymers Research Group”, 77317). Dr. Matthias Konrad and Prof. Dr. Klaus-Viktor Peinemann, from GKSS Forschungszentrum Geesthacht, are acknowledged for providing porous PAN/polyester support membranes and Dr. Sami Valkama and Antti Soininen from Helsinki University of Technology for experimental assistance and discussions. Work was supported by the Finnish Funding Agency for Technology and Innovation (HUMA project), Finnish Academy, and the European Commissionproject COMPOSE NMP3-CT-2003-505633.

\section{References and Notes}

(1) Gan, L. H.; Gan, Y. Y.; Deen, G. R. Macromolecules 2000, 33, 78937897.

(2) Inoue, T.; Chen, G.; Nakamae, K.; Hoffman, A. S. Polym. Gels Networks 1997, 5, 561-575.

(3) Nolan, C. M.; Serpe, M. J.; Lyon, L. A. Biomacromolecules 2004, 5, 1940-1946.

(4) Nakayama, M.; Okano, T. J. Drug Delivery Sci. Technol. 2006, 16, $35-44$.

(5) Dong, L. C.; Hoffman, A. S. J. Controlled Release 1991, 15, 141152.

(6) Chen, G.; Hoffman, A. S. Nature (London) 1995, 373, 49-52.

(7) Yang, B.; Yang, W. T. J. Membr. Sci. 2005, 258, 133-139.

(8) Torres-Lugo, M.; Peppas, N. A. Macromolecules 1999, 32, 66466651.

(9) Dagani, R. Chem. Eng. News 1997, 75, 26-37.

(10) Murdan, S. J. Controlled Release 2003, 92, 1-17.

(11) Osada, Y. In Polymer Gels and Networks; Marcel Dekker: New York, 2001.

(12) Lee, K.; Asher, S. A. J. Am. Chem. Soc. 2000, 122, 9534-9537.

(13) Yoshida, R.; Uesusuki, Y. Biomacromolecules 2005, 6, 2923-2926.

(14) Kokufata, E.; Zhang, Y.; Tanaka, T. Nature (London) 1991, 351, 302304.

(15) Miyata, T.; Jikihara, A.; Nakamae, K.; Hoffman, A. S. Macromol. Chem. Phys. 1996, 197, 1135-1146.

(16) Miyata, T.; Asami, N.; Uragami, T. Nature (London) 1999, 399, 766769.

(17) Juodkazis, S.; Mukai, N.; Wakaki, R.; Yamaguchi, A.; Matsuo, S.; Misawa, H. Nature (London) 2000, 408, 178-181.

(18) Plamper, F. A.; Walther, A.; Muller, A. H. E.; Ballauff, M. Nano Lett. 2007, 7, 167-171.

(19) Zhang, W. Q.; Shi, L. Q.; Ma, R. J.; An, Y. L.; Xu, Y. L.; Wu, K. Macromolecules 2005, 38, 8850-8852.

(20) Schilli, C. M.; Zhang, M. F.; Rizzardo, E.; Thang, S. H.; Chong, Y. K.; Edwards, K.; Karlsson, G.; Muller, A. H. E. Macromolecules 2004, 37, 7861-7866.

(21) Xu, F. J.; Kang, E. T.; Neoh, K. G. Biomaterials 2006, 27, 27872797.

(22) Mertoglu, M.; Garnier, S.; Laschewsky, A.; Skrabania, K.; Storsberg, J. Polymer 2005, 46, 7726-7740.

(23) Wu, C.; Wang, X. Phys. Rev. Lett. 1998, 80, 4092-4094.

(24) Taylor, L. D.; Cerankowski, L. D. J. Polym. Sci., Polym. Chem. Ed. 1975, 13, 2551-2570.

(25) Yin, X.; Hoffman, A. S.; Stayton, P. S. Biomacromolecules 2006, 7, $1381-1385$

(26) Matsen, M. W.; Thompson, R. B. J. Chem. Phys. 1999, 111, 71397146.

(27) Mortensen, K.; Brown, W.; Joergensen, E. Macromolecules 1994, 27, 5654-5666.

(28) Yoshida, T.; Kanaoka, S.; Watanabe, H.; Aoshima, S. J. Polym. Sci., Part A: Polym. Chem. 2005, 43, 2712-2722.

(29) Li, C. M.; Tang, Y. Q.; Armes, S. P.; Morris, C. J.; Rose, S. F.; Lloyd, A. W.; Lewis, A. L. Biomacromolecules 2005, 6, 994-999.

(30) Fujiwara, T.; Mukose, T.; Yamaoka, T.; Yamane, H.; Sakurai, S.; Kimura, Y. Macromol. Biosci. 2001, 1, 204-208.

(31) Li, C.; Buurma, N. J.; Haq, I.; Turner, C.; Armes, S. P.; Castelletto, V.; Hamley, I. W.; Lewis, A. L. Langmuir 2005, 21, 11026-11033. 
(32) Yoshida, T.; Kanaoka, S.; Watanabe, H.; Aoshima, S. J. Polym. Sci., Part A: Polym. Chem. 2005, 43, 2712-2722.

(33) Petka, W. A.; Harden, J. L.; McGrath, K. P.; Wirtz, D.; Tirrell, D. A. Science 1998, 281, 389-392.

(34) Kulkarni, S.; Schilli, C.; Grin, B.; Muller, A. H. E.; Hoffman, A. S.; Stayton, P. S. Biomacromolecules 2006, 7, 2736-2741.

(35) Stevens, M. M.; Allen, S.; Davies, M. C.; Roberts, C. J.; Sakata, J. K.; Tendler, S. J. B.; Tirrell, D. A.; Williams, P. M. Biomacromolecules 2005, 6, 1266-1271.

(36) Turner, J. S.; Cheng, Y. L. J. Membr. Sci. 1998, 148, 207-222.

(37) Lequieu, W.; Du Prez, F. E. Polymer 2004, 45, 749-757.

(38) Howse, J. R.; Topham, P.; Crook, C. J.; Gleeson, A. J.; Bras, W.; Jones, R. A. L.; Ryan, A. J. Nano Lett. 2006, 6, 73-77.

(39) Li, C.; Tang, Y.; Armes, S. P.; Morris, C. J.; Rose, S. F.; Lloyd, A. W.; Lewis, A. L. Biomacromolecules 2005, 6, 994-999.

(40) Satish Nayak, L. A. L. Angew. Chem., Int. Ed. 2005, 44, 7686-7708.

(41) Buguin, A.; Li, M. H.; Silberzan, P.; Ladoux, B.; Keller, P. J. Am. Chem. Soc. 2006, 128, 1088-1089.

(42) Ryan, A. J.; Crook, C. J.; Howse, J. R.; Topham, P.; Geoghegan, M. Martin, S. J.; Parnell, A. J.; Ruiz-Perez, L.; Jones, R. A. L. J. Macromol. Sci., Phys. 2005, B44, 1103-1121.

(43) Kikuchi, A.; Okano, T. Adv. Drug Delivery Rev. 2002, 54, 53-77.

(44) Ryan, A. J.; Crook, C. J.; Howse, J. R.; Topham, P.; Jones, R. A. L.; Geoghegan, M.; Parnell, A. J.; Ruiz-Perez, L.; Martin, S. J.; Cadby, A.; Menelle, A.; Webster, J. R. P.; Gleeson, A. J.; Bras, W. Faraday Discuss. 2005, 128, 55-74.

(45) Tsutsui, H.; Mikami, M.; Akashi, R. Adv. Mater. 2004, 16, 19251929.

(46) Fudouzi, H.; Xia, Y. Adv. Mater. 2003, 15, 892-896.

(47) Park, Y. S.; Ito, Y.; Imanishi, Y. Langmuir 1998, 14, 910-914.

(48) Yang, B.; Yang, W. J. Membr. Sci. 2003, 218, 247-255.

(49) Choi, Y. J.; Yamaguchi, T.; Nakao, S. Ind. Eng. Chem. Res. 2000 39, 2491-2495.

(50) Ying, L.; Kang, E. T.; Neoh, K. G.; Kato, K.; Iwata, H. J. Membr. Sci. 2004, 243, 253-262.
(51) Huang, J.; Wang, X.; Chen, X.; Yu, X. J. Appl. Polym. Sci. 2003, 89, 3180-3187.

(52) Peng, T.; Cheng, Y. L. Polymer 2001, 42, 2091-2100.

(53) Lequieu, W.; Shtanko, N. I.; Du Prez, F. E. J. Membr. Sci. 2005, 256 , 64-71.

(54) Zhang, K.; Huang, H.; Yang, G.; Shaw, J.; Yip, C.; Wu, X. Y. Biomacromolecules 2004, 5, 1248-1255.

(55) Rama Rao, G. V.; Lopez, G. P. Adv. Mater. 2000, 12, 1692-1695.

(56) Rama Rao, G. V.; Krug, M. E.; Balamurugan, S.; Xu, H. F.; Xu, Q.; Lopez, G. P. Chem. Mater. 2002, 14, 5075-5080.

(57) Rama Rao, G. V.; Balamurugan, S.; Meyer, D. E.; Chilkoti, A.; Lopez, G. P. Langmuir 2002, 18, 1819-1824.

(58) Dong, L. C.; Hoffman, A. S. J. Controlled Release 1990, 13, 21-31.

(59) Yoshida, R.; Uchida, K.; Kaneko, Y.; Sakai, K.; Kikuchi, A.; Sakurai, Y.; Okano, T. Nature (London) 1995, 374, 240-242.

(60) Kaneko, Y.; Nakamura, S.; Sakai, K.; Aoyagi, T.; Kikuchi, A.; Sakurai, Y.; Okano, T. Macromolecules 1998, 31, 6099-6105.

(61) Tanaka, T.; Fillmore, D. J. J. Chem. Phys. 1979, 70, 1214-1218

(62) Heijl, J. M. D.; Du Prez, F. E. Polymer 2004, 45, 6771-6778.

(63) Lai, J. T.; Filla, D.; Shea, R. Macromolecules 2002, 35, 6754-6756.

(64) Chiefari, J.; Chong, Y. K.; Ercole, F.; Krstina, J.; Jeffery, J.; Le, T. P. T.; Mayadunne, R. T. A.; Meijs, G. F.; Moad, C. L.; Moad, G.; Rizzardo, E.; Thang, S. H. Macromolecules 1998, 31, 5559-5562.

(65) Moad, G.; Rizzardo, E.; Thang, S. H. Aust. J. Chem. 2005, 58, 379410.

(66) Winey, K. I.; Thomas, E. L.; Fetters, L. J. Macromolecules 1992, 25, 2645-2650.

(67) Utracki, L. A. In Polymer Alloys and Blends: Thermodynamics and Rheology; Hanser Publishers: New York, 1989.

(68) Jones, R. A. L. In Polymers at Surfaces and Interfaces; Cambridge University Press: New York, 1999.

(69) Matsen, M. W. J. Chem. Phys. 1995, 102, 3884-3887. 